\title{
Kinetic Characterization of Leucurobin, a Coagulant Thrombin-Like Enzyme from the Venom of Bothrops leucurus
}

\author{
Henrique P. B. Magalhães ${ }^{*}, 1$, Matheus Philippe Teixeira de Sena ${ }^{1}$ and David Lee Nelson ${ }^{2}$ \\ ${ }^{1}$ Departamento de Análises Clínicas e Toxicológicas, Faculdade de Farmácia, Universidade Federal de Minas Gerais, \\ 31270-901 Belo Horizonte, MG, Brazil \\ ${ }^{2}$ Departamento de Alimentos, Faculdade de Farmácia, Universidade Federal de Minas Gerais, 31270-901 Belo \\ Horizonte, MG, Brazil
}

\begin{abstract}
In the present study, the kinetic characterization of leucurobin, a thrombin-like enzyme isolated from the venom of Bothrops leucurus was evaluated. This serpent is very common in the northeast of Brazil, but little is known about its venom. Leucurobin showed amidase activity against chromogenic substrates of the peptidyl-pNA type containing an Arg residue at P1. D-Phe-Pro-Arg-pNA was observed to be the best substrate of those tested. The amidase activity of leucurobin with this substrate was strongly inhibited by sodium and potassium ions and was weakly inhibited by calcium and magnesium ions. Leucurobin presented a high coagulating activity in vitro with citrated human plasma and with purified bovine fibrinogen. The coagulating activity with fibrinogen was inhibited by the presence of sodium and potassium ions, but not by calcium or magnesium ions. No interference in the amidase and coagulating activities by the glycoside fraction of native leucurobin was observed. The S1 site was found to be anionic, and the S2 and S3 sites are hydrophobic.
\end{abstract}

Keywords: Snake venom, thrombin-like enzymes, coagulation, kinetic characterization, Bothrops leucurus, synthetic substrates.

\section{INTRODUCTION}

The Bothrops leucurus (white tail lancehead) species is encountered throughout the region extending from the state of Ceara in the northeast of Brazil to the state of Espirito Santo in the east [1] in both humid and dry environments up to an altitude of 500 meters. It is found throughout the state of Bahia except for the São Francisco river valley and the extreme west. Of the venomous snakebites registered in Bahia in the period from 1982 to $1993,94 \%$ were caused by Bothrops leucurus and occurred within the metropolitan region of Salvador, Bahia [2-4].

The study of the proteases that are active in hemostasis can lead to a better understanding of the biochemical mechanisms involved in coagulation. In addition, such proteases have a potential for use as diagnostic reagents or as therapeutic agents. These proteases hydrolyze the fibrinogen. In vivo, this activity impedes the formation of a coagulum and thrombosis. The venoms of serpents of the Bothrops genus have been rich sources of these proteases and have presented a typical in vivo effect of intense bleeding resulting from the interaction of these proteases with various factors involved in the coagulation process. This interaction can disrupt the haemostatic equilibrium, possibly causing the death of the victim by extensive bleeding.

The biological effects of Bothrops leucurus venom are similar to those presented by other serpents of the Bothrops

*Address correspondence to this author at the Departamento de Análises Clínicas e Toxicológicas, Faculdade de Farmácia, Universidade Federal de Minas Gerais, 31270-901 Belo Horizonte, MG, Brazil; Tel: +55 31 34996894; Fax: +55 31 34996985; E-mail: hpbm@farmacia.ufmg.br genus, among them $B$. jararaca [5]. These activities include the in vitro coagulating activity against fibrinogen, hemorrhage, edema, tissue necrosis and renal failure. Prianti Jr. [6] demonstrated that the protein concentration of Bothrops leucurus venom is 1.16 times (calculated by current authors) greater than that of $B$. jararaca. The phospholipase $\mathrm{A}_{2}$ activity is also 9.5 times that of $B$. jararaca, while the proteolytic activity with casein is 1.6 times greater. Other effects described by this author include the decrease in the muscular contractibility of an avian neuromuscular preparation exposed to acetylcholine and potassium. This effect was probably caused by the action of venom proteases that could hydrolyze protein components of nicotinic receptors and proteins of the muscular fiber and membrane. The venom also caused histological alterations such as cellular vacuolization, compacted dark cells, damaged membranes, degradation of myofibrils and hypercontration of the muscular fibers in the muscle preparation. Creatine kinase-liberating activity of the preparation after incubation was also observed.

Another study [7] also demonstrated damage in muscle tissue employing the measurement of serum creatine kinase after intramuscular injection of the venom. Prianti [8] described the edematogenic activity of B. leucurus venom in rat paws in the presence of cyclooxygenase inhibitors, nitric oxide synthase inhibitors and anti-histamines and concluded that the venom caused edema in rat paws mediated by nitric oxide, histamine and metabolites formed from arachidonic acid by the action of cyclooxygenases.

Magalhães et al. [9] reported that leucurobin is a monomeric glycoprotein with a molecular weight of $35-\mathrm{kDa}$. The 
molecular weight decreased to 29-kDa after deglycosylation with N-glycosidase F (PNGase F). The authors determined the sequence of approximately $98 \%$ of the protease after digestion with endoproteases and separation of the peptide fragments. The authors observed that nearly $100 \%$ of the sequence was identical to that of batroxobin from the venom of Bothrops atrox. Leucurobin catalyzed the rapid hydrolysis of the alpha-chain of fibrinogen, liberating fibrinopeptide A, while the hydrolysis of the beta-chain to form fibrinopeptide $\mathrm{B}$ was much slower. The specific coagulating activity was $198 \mathrm{NIH}$ units/mg of human fibrinogen. Leucurobin did not activate the coagulation Factor XIII, nor did it liberate kinins from heat-treated bovine plasma. Four tripeptide substrates were used to kinetically characterize the enzyme: D-ValLeu-Arg-pNA, D-Pro-Phe-Arg-pNA, Bz-Phe-Val-Arg-pNA and D-Val-Leu-Lys-pNA. Leucurobin exhibited the greatest specificity for D-Val-Leu-Arg-pNA.

Among the snake venoms of the Bothrops genus, the venom of the Brazilian serpent Bothrops leucurus was chosen for study because of the fact that little was known about it, and the enzymatic activities associated with it are more accentuated than those of other Bothrops species. The general objective of this study was the biochemical characterization of leucurobin by kinetic studies with chromogenic substrates and with fibrinogen, the natural substrate for this enzyme.

It was necessary to extend the kinetic studies to substrates containing additional amino acid residues so as to identify the best peptidyl-pNA substrates for this protease. Eleven substrates were chosen from the substrate bank of this laboratory, and the kinetic parameters for their hydrolysis catalyzed by leucurobin were determined.

The activity of the enzyme with the best substrate of those tested was determined in the presence of increasing concentrations of mono- and divalent cations. The activities of bovine thrombin and bovine $\beta$-trypsin, enzymes whose active centers have been extensively described, were also determined with the same substrate. Finally, the activities of deglycosylated leucurobin against the chromogenic substrate and of native and deglycosylated leucurobin with citrated human plasma and purified human fibrinogen were determined.

\section{MATERIAL AND METHODS}

\subsection{Material}

A sample of leucurobin was furnished by the Fundação Ezequiel Dias, Belo Horizonte, MG, Brazil, after purification according to the procedure previously described by Magalhães et al. [9]. The sample exhibited a single band upon electrophoresis in polyacrylamide gel. A one- $\mathrm{mg} / \mathrm{mL}$ working solution of leucurobin in saline was prepared, divided into 15 aliquots and stored in the refrigerator for future use.

\subsubsection{Deglycosylated Leucurobin}

A leucurobin solution with a concentration of $0.903 \mathrm{mg}$ of protein $/ \mathrm{mL}$ was treated with PNGase to remove the glycosidic fraction from the enzyme. An aliquot of the same solution untreated with PNGase was used as a control.

\subsubsection{Chromogenic Substrates}

Solutions of 11 peptidyl-pNA substrates were prepared in $10 \%$ DMF in saline solution. The substrates utilized were Ac-Leu-Arg-pNa, Ac-His-Arg-pNA, Ac-Ala-Phe-Arg-pNA, D-Phe-Pro-Arg-pNA, Bz-Gly-Pro-Arg-pNA, Ac-Pro-PheArg-pNA, Bz-Pro-Phe-Arg-pNA, D-Phe-Leu-Arg-pNA, BzIle-Glu-Gly-Arg-pNA and D-Ile-His-Pro-Arg-pNA. The substrates were synthesized at the Laboratório de Síntese de Peptídeos do Departamento de Biofísica da Escola Paulista de Medicina - UNIFESP.

\subsubsection{Purified Bovine Fibrinogen Solution}

A solution containing $4.0 \mathrm{mg} / \mathrm{mL}$ of purified bovine fibrinogen was prepared in $0.1 \mathrm{M}$ Tris- $\mathrm{HCl}$ buffer, $\mathrm{pH}$ 8.0.

\subsubsection{Citrated Human Plasma}

Citrated human plasma was obtained by centrifugation of blood collected in sodium citrate from a fasting patient with normal haemostatic parameters.

\subsection{Methods}

\subsubsection{Determination of the Leucurobin Kinetic Parameters for the Peptidyl pNA Chromogenic Substrates}

The kinetic parameters of leucurobin for each of the 11 substrates were obtained by determining the initial velocity of hydrolysis at seven different concentrations of substrate and a constant enzyme concentration $(10 \mu \mathrm{g} / \mathrm{mL}, \mathrm{pH} 8.0,37$ $\left.{ }^{\circ} \mathrm{C}\right)$. The absorbance at $405 \mathrm{~nm}$ was determined on a Biotron BTR-310 spectrophotometer. The measurements were performed in duplicate and treated using the Cinética Enzimática SICEB software, which furnished the $\mathrm{K}_{\mathrm{m}}$ and $\mathrm{V}_{\max }$ values and permitted the calculation of $\mathrm{k}_{\mathrm{cat}}$ and $\mathrm{k}_{\mathrm{cat}} / \mathrm{K}_{\mathrm{m}}$. The conservation of the enzyme activity of the stored enzyme was accompanied by determining the rate of hydrolysis of Bz-L-Arg-pNA in parallel to the kinetic studies.

\subsubsection{Determination of $K_{m}$ for D-Phe-L-Pro-L-Arg-pNA with $\beta$-Trypsin and Human Thrombin}

The $K_{m}$ values for $\beta$-trypsin and human thrombin with the substrate D-Phe-L-Pro-L-Arg-pNA were obtained in the same manner as those for leucurobin (2.2.1).

\subsubsection{Determination of the Effect of Mono- and Divalent Cations on the Activity of Leucurobin}

The hydrolytic activities of leucurobin with D-Phe-ProArg-pNA in the presence of 0, 0.0377, 0.0755, and $0.1509 \mathrm{M}$ concentrations of $\mathrm{NaCl}, \mathrm{KCl}, \mathrm{MgCl}_{2}$ and $\mathrm{CaCl}_{2}$ were determined under the same conditions as those cited in section 2.2.1. The concentrations of substrate and enzyme were maintained constant.

\subsubsection{Determination of the Amidase Activity of Deglycosylated Leucurobin}

The activity of a solution containing $0.903 \mathrm{mg} / \mathrm{mL}$ of deglycosylated leucurobin was determined using D-Phe-ProArg-pNA as substrate. The initial concentration of substrate was $8.8 \times 10^{-4} \mathrm{M}$. The activity of a native enzyme solution at the same concentration was determined as a control (Section 2.2.1). 


\subsubsection{Determination of the Coagulating Activity of Native and Deglycosylated Leucurobin on Citrated Human Plasma}

The time necessary for the formation of a fibrin coagulum in citrated human plasma was determined after the addition of leucurobin $(10 \mu \mathrm{g} / \mathrm{mL}$ of citrated human plasma at $\mathrm{pH} 8.0$ and $\left.37^{\circ} \mathrm{C}\right)$.

\section{RESULTS}

The substrates that presented the highest values for the $\mathrm{k}_{\text {cat }} / \mathrm{K}_{\mathrm{m}}$ in the hydrolysis catalyzed by leucurobin were DPhe-Pro-Arg and D-Phe-Leu-Arg (Table 1). The highest affinity of the enzyme for the substrate was observed for DPhe-Pro-Arg. This affinity was greater than that shown by the classic serine proteases trypsin and bovine thrombin (Table 2).

Table 1. Leucurobin Kinetic Parameters for the Chromogenic Substrates Tested

\begin{tabular}{|c|c|c|c|c|c|c|c|}
\hline \multicolumn{5}{|c|}{ Relative position of the amino acid } & \multirow{2}{*}{$\begin{array}{c}\mathrm{K}_{\mathrm{m}} \\
(\mathrm{M}) \cdot 10^{-6} \pm \mathrm{SD}\end{array}$} & \multirow{2}{*}{$\begin{array}{l}\mathbf{k}_{\mathrm{cat}} \\
\left(\mathbf{s}^{-1}\right)\end{array}$} & \multirow{2}{*}{$\begin{array}{c}\mathbf{k}_{\mathrm{cat}} / \mathbf{K}_{\mathrm{m}} \\
\left(\mathbf{s}^{-1} \cdot \mathbf{M}^{-1}\right)\end{array}$} \\
\hline $\mathbf{P}_{5}$ & $\mathbf{P}_{4}$ & $\mathbf{P}_{3}$ & $\mathbf{P}_{2}$ & $\mathbf{P}_{1}$ & & & \\
\hline & & D-Phe & Pro & Arg & $15.2 \pm 1.0$ & 0.359 & 23618 \\
\hline & & D-Phe & Leu & $\operatorname{Arg}$ & $45.2 \pm 5.6$ & 0.815 & 18031 \\
\hline & Ile & His & Pro & $\operatorname{Arg}$ & $23.6 \pm 5.7$ & 0.087 & 3686 \\
\hline & & $\mathrm{Ac}$ & Leu & $\operatorname{Arg}$ & $842.1 \pm 244.3$ & 2.823 & 3352 \\
\hline & Ac & Ala & Phe & Arg & $532.6 \pm 59.4$ & 1.723 & 3235 \\
\hline & $\mathrm{Bz}$ & Gly & Pro & Arg & $54.5 \pm 12.5$ & 0.161 & 2954 \\
\hline \multirow[t]{5}{*}{$\mathrm{Bz}$} & Ile & Glu & Gly & $\operatorname{Arg}$ & $27.8 \pm 10.5$ & 0.036 & 1295 \\
\hline & Ac & Pro & Phe & $\operatorname{Arg}$ & $189.3 \pm 33.4$ & 0.241 & 1273 \\
\hline & & $\mathrm{Ac}$ & His & Arg & $209.5 \pm 66.3$ & 0.171 & 816 \\
\hline & & & $\mathrm{Bz}$ & Arg & $145.9 \pm 19.3$ & 0.113 & 775 \\
\hline & $\mathrm{Bz}$ & Pro & Phe & $\operatorname{Arg}$ & $371.8 \pm 78.3$ & 0.273 & 734 \\
\hline
\end{tabular}

Table 2. $\quad K_{m}$ Values of Leucurobin, $\beta$-Trypsin and Bovine Thrombin for D-Phe-Pro-Arg-pNA

\begin{tabular}{|c|c|}
\hline Enzyme & $\mathbf{K}_{\mathbf{m}}(\mathbf{M}) . \mathbf{1 0}^{-\mathbf{6}} \pm \mathbf{S D}$ \\
\hline \hline Leucurobin & $15.2 \pm 1.0$ \\
\hline Bovine $\beta$-Trypsin & $21.5 \pm 4.5$ \\
\hline Bovine thrombin & $41.2 \pm 5.6$ \\
\hline
\end{tabular}

\subsection{The Effects of Monovalent Cations $\left(\mathrm{K}^{+}\right.$and $\left.\mathrm{Na}^{+}\right)$on the Amidase Activity of Leucurobin}

The activity of leucurobin with D-Phe-Pro-Arg-pNA decreased in the presence of sodium and potassium ions (Table 3). The activities in the presence of $0.0377 \mathrm{M}$ concentrations of the sodium and potassium ions decreased to $83.1 \%$ and $67.5 \%$, respectively, of that observed in the absence of these ions. At an ion concentration of $0.0755 \mathrm{M}$, the residual activities were $62.4 \%$ for potassium ion and
$50.1 \%$ for sodium ion, and at a concentration of $0.1509 \mathrm{M}$, the activities were reduced to $51.1 \%$ for potassium ion and $39.1 \%$ for sodium ion. Thus, the reduction in activity was roughly proportional to the concentration of monovalent cation in the reaction medium.

Table 3. Relative Activity (\%) of Leucurobin with D-PhePro-Arg-pNA as a Function of the Concentrations of Mono- and Divalent Cátions*

\begin{tabular}{|c|c|c|c|c|}
\hline Concentration $(\mathbf{M})$ & $\mathbf{0}$ & $\mathbf{0 . 0 3 7 7}$ & $\mathbf{0 . 0 7 5 5}$ & $\mathbf{0 . 1 5 0 9}$ \\
\hline \hline Potassium & 100 & 83.1 & 62.4 & 51.1 \\
\hline Sodium & 100 & 67.5 & 50.1 & 39.1 \\
\hline Calcium & 100 & 33.3 & 23.6 & 19.9 \\
\hline Magnesium & 100 & 41.8 & 34.6 & 26.6 \\
\hline
\end{tabular}

There was also a decrease in the activity of leucurobin with the same substrate in the presence of the divalent calcium and magnesium cations. In the presence of 0.0377 $\mathrm{M}$ concentrations of these cations, the residual activities were $33.3 \%\left(\mathrm{Ca}^{+2}\right)$ and $41.8 \%\left(\mathrm{Mg}^{+2}\right)$. When the concentrations were increased to $0.0755 \mathrm{M}$, the activities were reduced to $23.6 \%\left(\mathrm{Ca}^{+2}\right)$ and $34.6 \%\left(\mathrm{Mg}^{+2}\right)$ of that observed in the absence of the cations. In the presence of $0.1509 \mathrm{M}$ cation, the residual activities were $19.9 \%$ for the calcium ion and $26.6 \%$ for magnesium ion. The effect of the divalent ions on leucurobin was greater than that of the monovalent cations at the same concentrations.

The effects of monovalent and divalent ions on the leucurobin activity against fibrinogen were also determined (Table 4). The concentration of ions utilized were the same as those used to determine their effects on the amidase activity. Both sodium and potassium ions inhibited the coagulating activity of leucurobin on fibrinogen, represented by an increase in the coagulation time with increasing concentrations of these cations. The coagulation times observed with sodium ion at the concentrations of $0.0 \mathrm{M}, 0.0377 \mathrm{M}$, $0.0755 \mathrm{M}$ and $0.1509 \mathrm{M}$ were 6.1 seconds, 9.5 seconds, 18.5 seconds and 29.2 seconds, respectively. The times observed with potassium ion at the same concentrations were 6.1 seconds, 11.4 seconds, 22.5 seconds and 24.2 seconds, respectively.

Table 4. Coagulation Times for Bovine Fibrinogen by Leucurobin as a Function of Mono- and Divalent Cations*

\begin{tabular}{|c|c|c|c|c|}
\hline \multirow{2}{*}{ Concentration (M) } & $\mathbf{0}$ & $\mathbf{0 . 0 3 7 7}$ & $\mathbf{0 . 0 7 5 5}$ & $\mathbf{0 . 1 5 0 9}$ \\
\cline { 2 - 5 } & \multicolumn{5}{|c|}{ Coagulation time (sec) } \\
\hline \hline Potassium & 6.1 & 11.4 & 22.6 & 24.2 \\
\hline Sodium & 6.1 & 9.5 & 18.5 & 29.2 \\
\hline Calcium & 6.1 & 6.0 & 7.1 & 9.2 \\
\hline Magnesium & 6.1 & 6.0 & 8.5 & 7.2 \\
\hline
\end{tabular}

*The values represent the means from three experiments. 
The divalent cations $\mathrm{Ca}^{+2}$ and $\mathrm{Mg}^{+2}$, on the other hand, did not inhibit the coagulating activity of leucurobin at the concentrations utilized. The use of magnesium ion at the same concentrations as those utilized for sodium and potassium ions resulted in coagulation times of 6.1 seconds, 6.0 seconds, 8.5 seconds and 7.2 seconds. The coagulation times obtained in the presence of calcium ion were 6.1 seconds, 6.0 seconds, 7.1 seconds and 9.2 seconds. These small differences are not significant for this type of analysis.

\section{DISCUSSION}

\subsection{The Effects of Substrate Structure on $\mathbf{K}_{\mathbf{m}}$}

According to previous observations by this group [9], the specificity constant for the hydrolysis of D-Val-Leu-ArgpNA catalyzed by leucurobin is 16 times greater that of DVal-Leu-Lys-pNA, a fact that indicates that there is a large preference for arginine over lysine at P1. However, the $\mathrm{K}_{\mathrm{m}}$ value for D-Val-Leu-Arg-pNA is 1.7 times greater than that of D-Val-Leu-Lys-pNA (57.1 $\mu \mathrm{M}$ and $99.0 \mu \mathrm{M}$, respectively). Although the affinity of leucurobin for D-Val-LeuLys-pNA is greater than that for D-Val-Leu-Arg-pNA, the value of $\mathrm{k}_{\text {cat }}$ for the latter substrate is approximately 28 times greater than that for the lysine residue at P1. Both substrates, being positively charged, can interact with the $\beta$-carboxylate group of $\mathrm{Asp}^{86}$ at sub-site $\mathrm{S} 1$ of the active center. Evidently, the stabilization of the transition state relative to the ground state is greater in the substrate having arginine at P1 than that bearing lysine at this position.

\subsubsection{S2-P2 Interaction}

The three substrates with proline at the $\mathrm{P} 2$ position had low $\mathrm{K}_{\mathrm{m}}$ values. The two substrates with the lowest $\mathrm{K}_{\mathrm{m}}$ values were D-Phe-Pro-Arg-pNA $(15.2 \mu \mathrm{M})$ and Ile-His-Pro-ArgpNA $(23.6 \mu \mathrm{M})$. The third substrate with proline at P2 was Bz-Gly-Pro-Arg-pNA, which exhibited a $\mathrm{K}_{\mathrm{m}}$ value of 54.5 $\mu \mathrm{M}$. The rigidity and relatively non-polar character of the proline side chain must contribute for the interaction with the S2 sub-site. Substrates with larger groups such as phenylalanine at this position presented higher $\mathrm{K}_{\mathrm{m}}$ values (Table $\mathbf{1}$ ), indicating that the presence of the larger phenyl ring decreased the affinity for the active center.

The kinetic parameters for two pairs of substrates that differ only at the P2 position were determined. For the first pair (D-Phe-Pro-Arg-pNA and D-Phe-Leu-Arg-pNA), the respective $\mathrm{K}_{\mathrm{m}}$ values were $15.2 \mu \mathrm{M}$ and $45.2 \mu \mathrm{M}$. Thus, the rigidity of the proline ring led to a decrease in $\mathrm{K}_{\mathrm{m}}$, although its polarity is roughly the same as that of leucine. The $\mathrm{K}_{\mathrm{m}}$ values for the second pair of substrates (Ac-His-Arg-pNA and Ac-Leu-Arg-pNA) were $209.5 \mu \mathrm{M}$ and $842.1 \mu \mathrm{M}$, respectively. Thus, the presence of histidine at $\mathrm{P} 2$ resulted in a higher affinity than that observed with leucine at this position. Although histidine is more polar than leucine, it also has a five-membered ring like proline and is more rigid than leucine. Thus, the explanation for the higher affinity of this substrate is similar to that for the substrate containing proline.

\subsubsection{S3-P3 Interaction}

Four substrates differing in the $\mathrm{P} 3$ position provided information with regard to the effect of residues in this position on the activity of leucurobin. The $\mathrm{K}_{\mathrm{m}}$ value for Ac-Leu-Arg-pNA was 19 times greater than that observed for D-Phe-Leu-Arg-pNA $(45.2 \mu \mathrm{M})$. The greater affinity of leucurobin for the substrate with D-phenylalanine in the P3 position may be a result of its greater volume, hydrophobicity and rigidity, as well as the presence of the $\alpha$-amino group and even the fact that it has the D configuration. The contribution of the last factor could be verified if the substrate with the enantiomeric residue in this position were tested.

The other pair of substrates was Ac-Pro-Phe-Arg-pNA, with a $K_{m}$ value of $189.3 \mu \mathrm{M}$, and Ac-Ala-Phe-Arg-pNA, whose $\mathrm{K}_{\mathrm{m}}$ value was equal to $532.6 \mu \mathrm{M}$, or about three times higher than that of the former substrate. Again, the substrate with the larger, more hydrophobic and more rigid side chain possessed the higher affinity for the S3 sub-site The higher affinity for the substrates with ring side chains is an indication that the S3 sub-site has a deep and hydrophobic pocket.

\subsubsection{S4-P4 Interaction}

The Ac-Pro-Phe-Arg-pNA substrate was seen to possess a greater affinity for the active site of the enzyme than BzPro-Phe-Arg-pNA, its $\mathrm{K}_{\mathrm{m}}(189.3 \mu \mathrm{M})$ being half that of the latter $(371.8 \mu \mathrm{M})$. This observation is probably a result of the greater size of the benzoyl group compared to that of the acetyl group. The greater hydrophobicity of the benzoyl group may also play a role if the site that must accommodate this residue is very polar. These observations suggest that S4 is not a very deep site, making it difficult for substrates with large groups to fit into the site.

\subsection{Comparison of Affinity of the D-Phe-Pro-Arg-pNA Substrate for Leucurobin, $\beta$-Trypsin and Bovine Thrombin}

The order of magnitude of the affinity of the substrate for these three proteases is similar (Table 2). This fact indicates that these three enzymes possess similar active centers that bind to the substrate with similar affinities. The higher affinity for leucurobin compared to the other two enzymes reinforces the conclusion that D-Phe-Pro-Arg-pNA is the most adequate substrate for this enzyme.

\subsection{The Effects of Substrate Structure on $\mathbf{k}_{\mathrm{cat}}$}

For comparison of $\mathrm{k}_{\text {cat }}$ values, the molar concentration of the active enzyme must be known. In the present work, the kinetic parameters were determined using the same enzyme solution, which was divided into aliquots. The solution was stored at $-20{ }^{\circ} \mathrm{C}$, and the hydrolytic activity against Bz-ArgpNA remained constant, so the various $k_{\text {cat }}$ values could be compared.

\subsubsection{S2-P2 Interaction}

The $\mathrm{k}_{\text {cat }}$ value obtained for D-Phe-Pro-Arg-pNA was $0.359 \mathrm{~s}^{-1}$, while that of D-Phe-Leu-Arg-pNA was $0.815 \mathrm{~s}^{-1}$ (Table 1). That is, the turnover velocity for the second substrate was twice that of the first. Thus, the velocity of the reaction with leucine in the $\mathrm{P} 2$ position was greater than that observed with proline in the same position. As seen previously (section 3.1.1), the presence of proline in this position lead to a greater affinity of the substrate for the 
active site. If the affinity of the active site for a certain substrate is very high, the relative affinity for the transition state will be lower. Thus, the difference in energy between the E-S complex and the transition state for the substrate with proline in the $\mathrm{P} 2$ position must be greater than that for the complex with leucine in this position.

The same is true for the substrate pair Ac-His-Arg-pNA and Ac-Leu-Arg-pNA, for which $\mathrm{k}_{\text {cat }}$ values of $0.171 \mathrm{~s}^{-1}$ and $2.823 \mathrm{~s}^{-1}$, respectively, were observed. The velocity of the reaction for the substrate with leucine in the $\mathrm{P} 2$ position was 16 times faster greater than that for the substrate with histidine in this position, although the substrate with histidine binds more strongly to the enzyme, as was shown above (section 3.1.1).

\subsubsection{S3-P3 Interaction}

Two pairs of substrates were used to determine the effect of amino acid residues in the P3 position on the turnover velocity of the substrate. In the first pair, a $\mathrm{k}_{\text {cat }}$ value equal to $0.241 \mathrm{~s}^{-1}$ was observed for the hydrolysis of the Ac-Pro-PheArg-pNA substrate, while a $\mathrm{k}_{\text {cat }}$ value of $1.723 \mathrm{~s}^{-1}$ was obtained for the reaction of Ac-Ala-Phe-Arg-pNA. Therefore, the presence of alanine at P3 favored the catalytic cycle seven times more than proline. The $K_{m}$ value for the hydrolysis of the substrate with proline in this position is one-third that of the substrate with alanine. Thus, the explanation for the difference in velocity is similar to that offered in the previous section.

In the second pair of substrates, D-Phe-Leu-Arg-pNA and Ac-Leu-Arg-pNA, the $\mathrm{k}_{\text {cat }}$ values observed were $0.815 \mathrm{~s}^{-1}$ and $2.823 \mathrm{~s}^{-1}$, respectively. The turnover velocity of the reaction with the substrate bearing acetyl in the $\mathrm{P} 3$ position is 3.5 times greater than that of the reaction of the substrate with D-phenylalanine, although its $\mathrm{K}_{\mathrm{m}}$ value is 18 times greater.

\subsubsection{S4-P4 Interaction}

Only one pair of substrates was tested to determine the influence of a group at $\mathrm{P} 4$ on the $\mathrm{k}_{\text {cat }}$ value: Bz- Pro-PheArg-pNA and Ac- Pro-Phe-Arg-pNA. The $\mathrm{k}_{\text {cat }}$ values observed for these substrates were $0.273 \mathrm{~s}^{-1}$ and $0.241 \mathrm{~s}^{-1}$, respectively. No terminal amino group is present in either of these substrates, and the effect of the volume of the $\mathrm{N}$-acyl group was very small.

The best indication of the specificity of an enzyme is the specificity constant given by $\mathrm{k}_{\text {cat }} / \mathrm{K}_{\mathrm{m}}$. The highest affinity for leucurobin was observed for D-Phe-Pro-Arg-pNA $\left(\mathrm{K}_{\mathrm{m}}=\right.$ $15.1 \mu \mathrm{M})$. Leucurobin binds to basic groups in $\mathrm{P} 1$, principally arginine and lysine, because of the presence of the $\beta$-carboxyl group of aspartate at S1. It also binds well to substrates having proline at the $\mathrm{P} 2$ position. The fourth highest $\mathrm{k}_{\mathrm{cat}}$ value among those observed under the conditions utilized was obtained for this substrate. Thus, the specificity constant calculated for this substrate was $23,618 \mathrm{~s}^{-1} \cdot \mathrm{M}^{-1}$.

The structure of this substrate is similar to that of D-PhePip-Arg-pNA, a substrate that mimics the sequence of amino acids in the peptide cleaved by thrombin when it activates Factor XIII. The difference is in the pipecolyl residue, which has one methyl group more than proline. In addition, the amino acid sequence of D-Phe-Pro-Arg-pNA is the same as that of an important irreversible inhibitor of thrombin, DPhe-Pro-Arg-CO- $\mathrm{CH}_{2}-\mathrm{Cl}$. Various competitive thrombin inhibitors that are available imitate this sequence and others are being investigated [10-12].

Thrombin had a high affinity for both D-Phe-Pro-Arg$\mathrm{CO}-\mathrm{CH}_{2}-\mathrm{Cl}$ and D-Phe-Pro-Arg-pNA $\left(\mathrm{K}_{\mathrm{m}}=41.2 \mu \mathrm{M}\right)$, which must possess a certain degree of complementarity to the active center of this enzyme. Since leucurobin also presented a high affinity for these substrates, one can infer that its active center is similar to that of thrombin.

However, although leucurobin exhibited a high activity for liberating fibrinopeptide A (FPA) from fibrinogen, it did not exhibit the same activity profile against the natural substrates of thrombin. The fact that it liberated fibrinopeptide B (FPB) very slowly and did not activate Factor XIII indicated that it was not highly active against the $\beta$-chain of fibrinogen [9].

The conclusion that the structures of the active centers of the two enzymes are similar, although leucurobin did not exhibit the same activity profile as thrombin with its natural substrates, should not be considered a contradiction. It is known that thrombin has two positively charged binding sites (exosites I and II) that are close to the catalytic site and that are important, among other factors, for the binding of thrombin to its natural substrates. These binding sites are not present in the SVTLEs, a fact that partially explains this apparent paradox between the similar activities of leucurobin and trombin with small substrates and the different activities with natural substrates.

Another thrombin-like enzyme that is irreversibly inhibited by D-Phe-Pro-Arg-CO- $\mathrm{CH}_{2}-\mathrm{Cl}$ is batroxobin from Bothrops atrox venom [13]. This fact suggests that this enzyme also has an active center topographically similar to those of thrombin and leucurobin.

Magalhães and coworkers [9] described the almost complete (96\%) sequence of amino acids in the primary structure of leucurobin and observed that this sequence is almost identical to that of batroxobin. This observation reinforced the supposition that there exists a high degree of similarity between the two enzymes.

This inference is important since batroxobin is used as a diagnostic tool to determine the fibrinogen content in heparinized patients, batroxobin not being inhibited by heparin. The similarity between the amino acid sequences of batroxobin and leucurobin indicates that leucurobin might also be employed in diagnostic tests to determine human fibrinogen.

The specificity constant of D-Phe-Leu-Arg-pNA was $18.031 \mathrm{~s}^{-1} \cdot \mathrm{M}^{-1}$, the second highest of the substrates tested. This substrate differed from the best substrate by having leucine in place of proline. This permutation lead to a decrease in affinity for the active center $\left(\mathrm{K}_{\mathrm{m}}\right.$ increased from 15.1 to $45.2 \mu \mathrm{M})$, but also caused an increase in the turnover $\left(\mathrm{k}_{\text {cat }}\right.$ increased from $0.359 \mathrm{~s}^{-1}$ to $\left.0.815 \mathrm{~s}^{-1}\right)$. Thus, the lower specificity constant for D-Phe-Leu-Arg-pNA relative to that observed with D-Phe-Pro-Arg-pNA was a result of the lower affinity of leucurobin for the former substrate. However, the difference in specificity constants was not large, contrary to those of the other substrates tested. Although leucine is not 
as rigid as proline, the side chains of the two amino acids are of similar size and polarity.

4.4 The Effects of Mono- and Divalent Cations $\left(\mathrm{Na}^{+}, \mathrm{K}^{+}\right.$, $\mathrm{Mg}^{+2}$ and $\mathrm{Ca}^{+2}$ ) on the Amidase Activity of Leucurobin

There are two manners by which these ions may diminish the activity of leucurobin. One would be by competitively interacting with the $\beta$-carboxylate group of the aspartate residue in the active center. The other would be by causing a change in conformation of the enzyme molecule by interacting with negatively charged groups, thereby reducing the electrostatic interactions that maintain its three dimensional structure. In either case, divalent cations would have a greater effect than monovalent cations because solutions of the former would have a higher ionic strength than those of the latter at the same concentration.

\subsection{Amidase Activity of Deglycosylated Leucurobin}

Deglycosylated leucurobin presented an activity similar to that of the native enzyme with equimolar solutions of DPhe-Pro-Arg-pNA, the deglycosylated enzyme having an activity equal to $90.5 \%$ that of the native enzyme. This observation indicated that the carbohydrate coat that covers the native enzyme has no participation in the coupling with the small substrates and its absence did not interfere with the leucurobin activity. It would appear that the glycoside portion was bound to a region sufficiently distant from the active center that it did not interfere in the activity with small substrates.

\subsection{Coagulating activity on Citrated Human Plasma}

The tests with purified leucurobin revealed that this protease has a strong in vitro activity against citrated human plasma. As can be seen in Table 4, the average coagulation time was approximately eight seconds. The components in the citrated plasma did not inhibit the activity of leucurobin. The components that could exercise some inhibitory activity against leucurobin are the serpines (serine protease inhibitors), proteins present in blood plasma that frequently inhibit the activity of coagulases from serpent venom. The principal serpines are $\alpha_{2}$-macroglobulin and $\alpha_{1}$-antitrypsin. This characteristic of leucurobin is also similar to that of thrombin.

Citrate complexes with nearly all the plasmatic calcium and, thereby, inhibits various factors that are calcium-dependent and are important for the coagulation cascade. However, that last step of the cascade (hydrolysis of fibrinogen and polymerization of the fibrin monomers), which is catalyzed by thrombin, does not depend on calcium. Leucurobin is also similar to thrombin in this aspect since it also acts upon fibrinogen in the absence of calcium.

The coagulating activity of deglycosylated leucurobin on citrated plasma was not significantly different from that of the native enzyme. The coagulation time ( 7.8 seconds) was similar to that of the native enzyme $(8.2$ seconds) when equal concentrations of both forms of the active enzyme were utilized. This observation signifies that the glycoside fraction of native leucurobin did not participate in the interaction with fibrinogen and must be bound at a point that is distant from the active center.

\subsection{Coagulating Activity Against Bovine Fibrinogen}

The native and deglycosylated forms of leucurobin also presented coagulating activity on a $4.0 \mathrm{mg} / \mathrm{mL}$ solution of bovine fibrinogen, with coagulating times of 6.5 seconds and 6.4 seconds, respectively. Thus, the glycoside fraction again had no effect on the activity.

\subsection{Effect of Mono- and Divalent Ions on the Coagulating Activity of Leucurobin}

The effect of sodium and potassium ions on the coagulating activity may be explained in the same way as their effects on the amidase activity against a small substrate. The observation that the divalent cations had no effect on the coagulating activity catalyzed by leucurobin may be explained by the coagulation process. The final process in the formation of the coagulum may be resumed in three basic steps [14]:

1. proteolysis of fibrinogen, liberating fibrinopeptide $A$ (thrombin also liberates fibrinopeptiede B by cleavage of the $\beta$-chain). This act exposes new bonding sites in the central region of the cleaved fibrinogen molecule, the monomers of fibrin.

2. spontaneous polymerization of the fibrin monomers to form protofibrils through non-covalent interactions between the exposed regions and complementary sites on the fibrin molecule;

3. stabilization of the fibrin network by Factor XIII , which promotes the formation of covalent bonds between the $\alpha$ - and $\gamma$-chains.

A solution of purified bovine fibrinogen without Factor XIII was used in the experiment to determine the influence of cations on the coagulating activity. Therefore, the last step, which requires Factor XIII, did not occur, and the coagulation time depended only upon the first two steps, the proteolysis of fibrinogen and the polymerization of the fibrin monomers. The role of leucurobin is limited to the proteolysis of fibrinogen. The polymerization step is spontaneous and is accelerated by the presence of calcium ions, as was shown by Brass and collaborators [15]. These workers demonstrated that calcium ion is not necessary, but accelerates the polymerization of fibrin when it is present. Kanaide and coworkers [16] showed that, not only calcium, but various divalent cations, including zinc, accelerated the polymerization of fibrin. Masahisa and collaborators [17] described the reduction of the coagulation time by magnesium and calcium ions, while Marx [18,19] reported that a $0.5 \mathrm{mM}$ concentration of magnesium ion did not significantly alter the formation of the fibrin coagulum.

Thus, although calcium inhibited the fibrinogen proteolysis activity of leucurobin by competitive inhibition and possible effects on the molecular conformation, its accelerating effect on the polymerization of fibrin monomers compensated for the inhibitory effects so that the overall rate was the same as that obtained in the absence of calcium ion. The same can be said about the effect of magnesium, although 
there is some controversy with respect to its accelerating effect on the polymerization of fibrin.

\section{CONCLUSIONS}

Leucurobin has an aspartate residue at S1 that directs its specificity to chromogenic and natural substrates containing arginine or lysine residues at P1, the S1-P1 interaction being electrostatic. S1 is sufficiently deep to accommodate the arginine side chain and the enzyme is most active against substrates having this amino acid in the P1 position. In general, those substrates with the lowest $\mathrm{K}_{\mathrm{m}}$ values did not present the highest catalytic constants with leucurobin. The highest $\mathrm{k}_{\mathrm{cat}}$ values were obtained when the enzyme-transition state complex is stabilized more than the enzyme-substrate complex. The S2-P2 interaction is hydrophobic. The S2 site for leucurobin is not very deep so that it only accommodates small or medium size residues. The rigidity of the proline ring at this position evidently aids in the spatial orientation of the substrate in the active center. The increase in affinity of the active center for the substrate with proline at P2 is more important than the decrease in $\mathrm{k}_{\mathrm{cat}}$ caused by this residue relative to that of leucine, resulting in a higher specificity constant. The S3-P3 interaction is hydrophobic, and the S3 sub-site is sufficiently deep to accommodate larger residues such as phenylalanine. The substrate with the highest specificity constant among those tested with leucurobin was D-Phe-Pro-Arg-pNA. This activity was inhibited by cations, the inhibition by divalent cations being greater than that of monovalent cations. Leucurobin had a high coagulating activity against citrated human plasma and purified bovine fibrinogen. This activity was strongly inhibited by sodium and potassium ions, while the inhibition by calcium and magnesium ions was weak. The kinetic parameters and the active center of leucurobin are very similar to those of thrombin and batroxobin.

\section{REFERENCES}

[1] Lira-da-Silva RM, Andrade-Lima R, Brazil TK. Distribuição Geográfica de Bothrops leucurus (Serpentes; Viperidae). Resumos do IV Congresso Latinoamericano de Herpetologia, 1996. Santiago, Chile. Sociedade Latinoamericana de Zoologia 1996; p. 153.

[2] Lira-da-Silva RM, Nunes TB. Ophidic accidents by Bothrops leucurus Wagler, in Bahia. Brazil Toxicol (Oxford) 1993; 31: 1434.
[3] Lira-da-Silva RM, Lima RA, Nunes TB. Envenomations caused by Bothrops leucurus Wagler, 1824 (Serpentes, Viperidae) in Metropolitan Region of Salvador, Bahia. Rev Soc Bras Med Trop 1994; 27: 124.

[4] Lira-da-Silva RM. Estudo Clínico-Epidemiológico dos Acidentes por Bothrops leucurus na região metropolitana de Salvador, Bahia. Salvador. Mestrado em Medicina Preventiva. Universidade Federal da Bahia 1996; p.154.

[5] Sanchez EF, Freitas TV, Ferreira-Alves DL, et al. Biological activities of venoms from South American snakes. Toxicon 1992; 30: 95-103.

[6] Prianti-Jr ACG, Ribeiro W, Lopes-Martins RAB, et al. Effect of Bothrops leucurus venom in chick biventer cervicis preparations. Toxicon 2003; 41: 595-603.

[7] Mise YF, Casais-E-Silva LL, Barbosa A, Lira-Da-Silva RM. Skeletal muscle damage caused by Bothrops leucurus (Serpentes; Viperidae) venom. J Venom Anim Toxins Incl Trop Dis 2003; 9: 448.

[8] Prianti-Jr ACG, Barbosa AM, Labat MR, et al. Pharmacological characterization of the mouse paw edema induced by Bothrops leucurus (white-tailed jararaca) venom. J Venom Anim Toxins Incl Trop Dis 2004; 10: 468.

[9] Magalhães A, Magalhães HPB, Richardson M, et al. Purification and properties of a coagulant thrombin-like enzyme from the venom of Bothrops leucurus. Comp Biochem Physiol Part A 2007; 146: $565-75$.

[10] Bode W, Turk D, Karshikov A. The refined X-ray crystal structure of D-Phe-Pro-Arg chloromethylketone-inhibited human $\alpha$-thrombin: structure analysis, overall structure, electrostatic properties, detailed active-site geometry and structure-function relationships. Protein Sci 1992; 1: 426-71.

[11] Lange UEW, Baucke D, Hornberger W, et al. D-Phe-Pro-Arg type thrombin inhibitors: unexpected selectivity by modification of the P1 moiety. Bioorg Med Chem Lett 2003; 13: 2029-33.

[12] Marinko P, Krbavcic A, Mlinsek G, et al. Novel non-covalent thrombin inhibitors incorporating $\mathrm{P}_{1}$ 4,5,6,7-tetrahidrobenzothiazole arginine side chain mimetics. Eur J Med Chem 2004; 39: 257-65.

[13] Stürzebecher J, Stürzebecher U, Mark WF. Inhibition of batroxobin, a serine protease from Bothrops snake venom by derivatives of benzamidines. Toxicon 1986; 4: 585-95.

[14] Côté HCF, Lord ST, Pratt KP. $\gamma$-Chain Dysfibrinogenemias: molecular structure-function relationships of naturally occurring mutations in the $\gamma$ Chain of human fibrinogen. Blood 1998; 92: 2195-12.

[15] Brass EP, Forman WB, Edwards RV, Lindan O. Fibrin formation: effect of calcium ions. Blood 1978: 52: 654-8

[16] Kanaide H, Uranishi T, Nakamura M. Effect of divalent cátions on the conversion of fibrinogen to fibrin and fibrin polymerization. Am J Haematol 1982; 13: 229-37.

[17] Masahisa O, Blomback, B. Calcium and fibrin gel structure Thromb Res 1983; 29: 269-80.

[18] Marx G. Mechanism of fibrin coagulation based on selective, cation-driven, protofibril association. Biopolymers 1988; 27(5): 763-74.

[19] Marx G. Divalent cations induce protofibril gelation. Am J Hematol 1988; 27: 104-9.

\section{(C) Magalhães et al.; Licensee Bentham Open.}

This is an open access article licensed under the terms of the Creative Commons Attribution Non-Commercial License (http://creativecommons.org/licenses/by$\mathrm{nc} / 3.0 /$ ), which permits unrestricted, non-commercial use, distribution and reproduction in any medium, provided the work is properly cited. 